\title{
How healthy are children's menus on the island of Ireland?
}

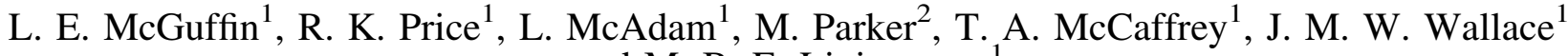 \\ and M. B. E. Livingstone ${ }^{1}$ \\ ${ }^{1}$ Northern Ireland Centre for Food and Health, University of Ulster, Coleraine, BT52 ISA and ${ }^{2}$ Postgraduate Medical \\ Research Institute, Anglia Ruskin University, Chelmsford, UK
}

Out-of-home $(\mathrm{OH})$ eating has been identified as one of the many contributing factors to the development of obesity ${ }^{(1)}$. It has been reported that $77 \%$ of Irish children ate $\mathrm{OH}$ at least once a week and this contributed $10 \%$ of energy intakes ${ }^{(2)}$. Although, the current literature has demonstrated that the majority of children's menus are of low nutritional quality ${ }^{(3-5)}$, there are no comparable data for the island of Ireland. Therefore, the aim of this study was to assess children's menus on the island of Ireland by scoring the availability of healthier menu choices.

Children's menus ( $n 106)$ from a range of establishment types (cafes/sandwich shops, fast food establishments, restaurants and pubs) across the island of Ireland were scored. The scoring criteria were based on the children's menu section of the Northern Ireland Nutrition Catering Award $^{(6)}$. Questions included the availability of half portions and healthier menu items e.g. fruit, yogurt, milk, water. Menus were awarded scores based on not meeting, partially meeting and fully meeting the criteria out of a possible, maximum score of 15 . A Fisher's Exact Test was used to explore the association of scores between establishment type and a one way ANOVA with a permutation test identified any significant differences between establishment total scores.

In general, all four types of establishments scored low for the provision of healthier options (mean/15 (SD)); (4 (3.1), range 0-14): Cafes/sandwich shops $(5.3$ (3.0)) $>$ Restaurants $(4.5(3.3))>$ Pubs $(4.5(2.8))>$ Fast food $(1.8(2.1))$. The total score for fast food establishments was significantly lower than cafes/sandwich shops and pubs $(P=0.001)$. Although the majority of establishments did not fully meet all of the criteria, some establishments were more likely to provide an alternative to deep fried potatoes but least likely to provide both fruit and yogurt (Table). Fast food establishments were least likely to meet the criteria except for provision of milk and water (Table).

Table. Percentage of establishments fully meeting each criterion.

\begin{tabular}{lcrrr}
\hline Criteria & $\begin{array}{c}\text { All establishments } \\
(n 106 ; \%)\end{array}$ & $\begin{array}{c}\text { Cafe } \\
(n 10 ; \%)\end{array}$ & $\begin{array}{c}\text { Fast food } \\
(n 24 ; \%)\end{array}$ & $\begin{array}{c}\text { Restaurant } \\
(n 49 ; \%)\end{array}$ \\
\hline Are at least 50\% of meals healthy? & 22 & 50 & 0 & 29 \\
Is there a vegetable apart from beans? & 13 & 10 & 0 & 17 \\
Are fruit \& yogurt available? & 2 & 10 & 0 & 29 \\
Are milk \& water available? & 16 & 0 & 2 & 4 \\
Is there an alternative to deep fried potatoes? & 25 & 10 & 0.001 \\
Are there half portions of adult menu? & 13 & 10 & 0.047 \\
\hline
\end{tabular}

aA Fisher's Exact Test identified any associations between establishment type scores for each criterion.

This research has revealed children's menus on the island of Ireland were limited in both menu choice and nutritional quality. Small changes such as providing vegetables, milk, water, fruit and yogurts as standard menu items could improve the nutritional value of OH food served to children.

This material is based upon works supported by safefood, the Food Safety Promotion Board, under Grant No. 10-2009.

1. World Health Organisation (2007) Copenhagen: WHO Regional Office of Europe.

2. Irish Universities Nutrition Alliance (2005) Dublin: IUNA.

3. Saelens BE, Glanz K, Sallis JF et al. (2007) Am. J. Prev. Med. 32, 273-281.

4. O’Donnell SI, Hoerr SL, Mendoza JA et al. (2008) AJCN. 88, 1388-1395.

5. Krukowski RA, Eddings K \& Smith West D (2011) J. Am. Diet. Assoc. 111, 884-888

6. Northern Ireland Nutrition Working Group (2011) Northern Ireland Nutrition Award Scheme. 